\title{
Comparative Analysis on Seismicity and Stress Triggering of Strong Earthquakes Sequence in Central Tibet
}

\author{
Gang Yang ( $\square$ yangg8710@126.com ) \\ Institute of Seismology China Earthquake Administration \\ Dongning Lei \\ Institute of Seismology China Earthquake Administration \\ Jianchao Wu \\ Institute of Seismology China Earthquake Administration
}

\section{Research Article}

Keywords: Central Tibet, Seismicity, Coulomb stress change, Seismic hazard

Posted Date: September 9th, 2021

DOI: https://doi.org/10.21203/rs.3.rs-870372/v1

License: (c) (i) This work is licensed under a Creative Commons Attribution 4.0 International License. Read Full License 


\section{Abstract}

The Central Tibet constitutes part of the central part of Qinghai-Tibetan Plateau, which is one of the highest seismic activity areas in China. This paper discussed the regularity of seismic activity in this area. Based on a stratified viscoelastic earth model, we calculated the Coulomb stress changes imparted from the 4 strong earthquakes $(M \geq 6.3)$ the Bengco - southeastern piedmont of Nyainqentanglha mountain fault zone in this region. The result shows that the study area may enter a new active period from 2020 . There was a trigger between strong earthquakes (M $\geq 6.3$ ) on the Bengco fault southeastern piedmont of Nyainqentanglha mountain fault zone. The post-seismic viscous relaxation effect of a strong earthquake had a significant impact on subsequent earthquakes(M $\geq 6.3)$. In future 100 years, the Coulomb stress loading is more than $1.0 \mathrm{MPa}$ in northwest section of Bengco fault and central of Nimu segment of southeastern piedmont of Nyainqentanglha mountain fault, thence strong earthquakes may occur in this two fault segments. The maximum magnitude of the earthquake will be M6.7 in the future 100 years.

\section{Introduction}

Central Tibet has strong tectonic activity and frequent strong earthquakes (Figure 1). In recent years, the spatiotemporal relationship between Coulomb stress changes caused by earthquakes and subsequent earthquakes has attracted widespread attention from seismologists(Gomberg and Felzer, 2008; Harris, 1998; Shan et al., 2020; Yang et al., 2019; Yin et al., 2018). Studies have shown that small Coulomb stress changes (threshold is $0.01 \mathrm{MPa}$ ) may trigger earthquakes(Harris, 1998; Stein, 1999), leading to the change of future seismic activity in the region.

The crustal deformation of the study area mainly develops a series of near S-N tectonic belts(Jiao et al., 2015), and NW, NE tectonic belts. The Yangbajain-Damxung basin is located in the north-central part of the Yadong-Gulu Rift Valley system. It is $120 \mathrm{~km}$ long and $10-25 \mathrm{~km}$ wide(Qiao et al., 2009).

The Damxung M8.0 earthquake in 1411, the Bengco M7.7 earthquake in 1951, the Gulu M7.4 earthquake in 1952, and the Damxung M6.3 earthquake in 2008 had occurred on the Bengco - southeastern piedmont of Nyainqentanglha mountain (B-SPNM) fault zone in study area, which are (Figure 1).

Figure 1 Seismotectonic map of the central Tibet. F1 is the YarlungZangbo fault, F2 is the SPFNM (F2-1 Nimu segment, F2-2 DamxungYangbajain segment, F2-3 Gulu segment), F3 is the Bengco fault. DEM data from(CGIAR-CSI, 2020).

In this paper, the impact of the four earthquakes on the surrounding area will be analyzed by calculating the Coulomb stress changes after the earthquake. This study will be of great scientific significance for understanding seismic activity in the region and estimating future seismic hazards of fault zones.

Seismic activity research

Seismic data and integrity analysis

The seismic data are mainly acquired through citing and checking the Catalogue of Chinese Historical Strong Earthquakes (23rd century BC-1911 AD) (Administration, 1995), Catalogue of Chinese Modern Earthquakes (1912 AD-1990 AD)(Administration, 1999), Catalogue of Chinese Earthquakes (1831 BC-1969 AD)(Gu, 1983), and the catalogue of earthquakes of China Earthquake Network Center (CENC, 2020) and the catalogue of world earthquakes provided by USGS(USGS, 2020).

This study area has very few historical records of earthquakes, among which the early seismic data are missing, that of the earthquakes lower than M5 is seriously missing and the record of the destructive earthquakes originated from $1411 \mathrm{AD}$. Along with the gradual establishment of the earthquake networks around the world since 1900, the seismic records observed by instruments started from 1950 in this area and the strong earthquakes from then on have instrument-observed data, from which it is estimated that the possibility of omitted records of earthquakes over M5 is very low. Judging from the seismic records, the earthquakes of $M \geq 5$ of this area are basically complete since 1950 , and the earthquakes of $M \geq 2$ of this area are basically complete since 1970 . The seismic data could be used as the reference basis for the study of the seismic activity and the estimation of their parameters in this area.

Characteristics of earthquake temporal distribution

According to historical seismic data, the earliest occurred earthquake in the area was Duilongdeqing M6 earthquake in 1264 . Figure 2a shows the M-T diagram of $M \geq 4$.7earthquakes in the central Tibet since 1200. Between 1200 and 1900, only 9 earthquakes were recorded, indicating that the seismic data were seriously lacking. However, the Damxung M8 earthquake record in 1411 was more detailed(Wu et al., 1992). It is clearer from Figure $2 b$ that the area has experienced two seismically active periods since 1900, with the first active period from 1920 to 1960 and the second active period from 1970 to the present. The study area is at the end of the second active period. From a conservative point of view, at present, the trend of seismic activity in the study area in the next hundred years should be estimated based on the average seismic activity level of the earthquake statistical area. It may be at the beginning of a new active period.

Figure 2 (a) M-T maps of the study area since 1200; (b) M-T maps of the study area since 1900

Statistics of $a$-value and $b$-value of seismicity parameters 
The Gutenberg-Richter magnitude-frequency relationship is Equation (1)(Gutenberg and Richter, 1956):

$\operatorname{Lg} N=a-b M(1)$

Where $N$ is the number of cumulative earthquakes with magnitude greater than $M$, and $a$ and $b$ are statistical constants, where $a$ is the intercept in the magnitude-frequency relationship, which represents the total number of earthquakes in the area or the severity of the frequency of seismic activity. The $b$ value is the slope in the magnitude-frequency relationship, which represents the ratio of different magnitude earthquake frequencies in an area. It is obtained from actual data statistics.

According to the seismic data integrity analysis and time distribution characteristics of the study area, the cumulative annual average incidence ( $V$ ) of earthquakes in different periods of the study area was calculated. The calculation results are shown in Table 1.

Table $1 \mathrm{~A}$ cumulative annual mean incidence of earthquake in different time period of Central Tibet

The least squares method is used to fit the data in each period to form a variety of statistical schemes. After comparative analysis, the best fitting scheme is finally selected, then $a$ and $b$ values of the study area are statistically obtained. $a=4.240$, and its standard error is 0.038 . $b=0.530$, its standard error is $0.007, R$ is the correlation coefficient, $S D$ is the sum of the squared residuals, and the fit is shown in Figure 3

\section{Coulomb Stress Change Calculation}

Research method

According to the stress triggering theory of the earthquake, the stress accumulated on the fault plane is released when the earthquake occurs. Part of the stress will be transferred to the area around the seismic rupture surface, which will change the state of the stress field and further affect the seismicity of the future(Stein, 2003). Using elastic dislocation theory, we can obtain the Coulomb stress field changes caused by earthquakes.

The expression of the static Coulomb stress change is Equation 2:

$\Delta C F S=\Delta \tau_{s}+\mu^{\prime} \Delta \sigma_{n} \quad(2)$

Where, $\triangle$ CFS is the Coulomb stress changes on the fault plane, $\Delta \tau_{s}$ is the shear stress variation on the fault plane, $\mu^{\prime}$ is the effective friction coefficient of the fault, $\Delta \sigma_{n}$ is the normal stress variation on the fault plane, and the tensile is positive. In this study, $\mu^{\prime}=0.4$ (King et al., 1995; Stein et al., 1992; Verdecchia and Carena, 2015). This calculate uses a PSGRN/PSCMP calculation program(Wang et al., 2006) that is based on a layered, gravity viscoelastic earth model, which can be used to study co-seismic and post-seismic Coulomb stress field changes caused by strong earthquakes.

Lithosphere layered structure parameters

Based on the research results of the P-wave velocity and crustal density structure model below the Lhasa block(Christensen and Mooney, 1995; Haines et al., 2003; Zhao et al., 2001), and the average crustal velocity ratio $V_{P}=1.73 V_{S}$ model(Wang et al., 2008), the crustal velocity and density models of the study area were determined. In this paper, the Maxwell volume rheological model is used to simulate the viscoelastic effects of the lower crust and mantle over decades to hundreds of years. Due to the high crust thickness and high temperature on the Tibetan Plateau, the lower crust viscosity coefficient is low. The crustal viscosity coefficient is $1.0 \times 10^{20} \mathrm{~Pa} \cdot \mathrm{s}$. The mantle viscosity coefficient is one order of magnitude higher than that of the lower crust, namely $1.0 \times 10^{21} \mathrm{~Pa} \cdot \mathrm{s}$. The middle and upper crust is a completely elastic medium, in which the viscosity coefficient is infinite(Shi and Cao, 2008; Yin et al., 2018). Table 2 shows the parameters of the multilayer crustal model.

Seismic dislocation model

The dislocation model of Damxung M8.0 earthquake in 1411, Bengco M7.7 earthquake in 1951, and Gulu M7.4 earthquake in 1952 refer to the fault fracture model proposed by Yang et.al(Yang et al., 2019). The strike, dip, rake and maximum slip of seismogenic fault of Damxung M6.3 earthquake in 2008 are $183.3^{\circ}, 49.5^{\circ},-115^{\circ}$, and $1.30 \mathrm{~m}$ respectively(Gao et al., 2010), and he length is $12 \mathrm{~km}$ and the width is $11 \mathrm{~km}($ Qiao et al., 2009 ). Table 3 shows the data of the 4 strong earthquake dislocation models.

Stress evolution and earthquake triggering

According to the parameters listed in Table 3, we calculated the Coulomb stress changes on the fault plane of the four earthquakes caused by the postseismic dislocation of each earthquake in chronological order (Figure 4).

The red beach ball represents the focal mechanism of the receive fault, the gray beach ball represents the focal mechanism of the seismogenic fault. (a) Coulomb stress changes on the 1951 M7.7 earthquake's fault plane associated with the post-seismic viscoelastic relaxation of the 1411 M8.0 earthquake, the calculated depth is $30.0 \mathrm{~km}$. (b) Coulomb stress changes on the $1952 \mathrm{M7} .4$ earthquake's fault plane associated with the post-seismic viscoelastic relaxation of the 1411 M8.0 earthquake and 1951 M7.7 earthquake, the calculated depth is $25.0 \mathrm{~km}$. (c) Coulomb stress changes on the 2008 M6.3 earthquake's fault plane associated with the post-seismic viscoelastic relaxation of prior earthquakes before the $2008 \mathrm{M} 6.3$ earthquake, the calculated depth is $9.5 \mathrm{~km}$. 
Figure 4a shows that the Bengco M7.7 earthquake in 1951 was located in the area where the post-seismic Coulomb failure stress was significantly increased due to the Damxung M8.0 earthquake in 1411. The Coulomb stress at the center of the rupture increased $0.143 \mathrm{MPa}$. Figure $4 \mathrm{~b}$ shows that the Gulu M7.4 earthquake in 1952 was also located in the area where the post-seismic Coulomb failure stress was significantly increased due to the Damxung M8.0 earthquake in 1411 and the Bengco M7.7 earthquake in 1951. The Coulomb stress at the center of the rupture increased 0.136 MPa. Figure 4c shows that the Damxung M6.3 earthquake in 2008 was also located in the area where the post-seismic Coulomb failure stress was slightly increased due to prior earthquakes before the 2008. The Coulomb stress at the center of the rupture increased $0.279 \mathrm{MPa}$.

In order to calculate the effect of four strong earthquakes on a fault zone, the parameters of the receiving fault must be known. The main fault sliding properties and parameters in the study area are shown in Table 4.

F1 from(Peng and Wang, 2013) , F2-1, F2-2, F2-3 and F3 from(Wu et al., 1992; Yang et al., 2019)

Figure 5 shows the distribution of Coulomb stress changes on the three fault zones after the Damxung M6.3 earthquake in 2008 due to the 4 strong earthquakes.

Coulomb stress changes are calculated at a depth of $10 \mathrm{~km}$. The beach balls show mechanisms of the 4 strong earthquakes. (a) - (d) display the stress state in $2033,2058,2083$ and 2108 , respectively. The red box is the research range of the stress gradually increasing from the untriggered value to the trigger value.

Based on the combined effects of 4 earthquakes, this paper analyzes the future Coulomb stress changes (from 2033 AD to 2108 AD) of each fault. The east and west ends of the YarlungZangbo fault (F1) will be gradually change from stress loading $(0 \sim 0.01 \mathrm{MPa}, 2033 \mathrm{AD} \sim 2083 \mathrm{AD})$ to stress unloading $(-0.01 \sim 0 M P a, 2108 A D)$. The Coulomb stress in the south of F2-1 will be continuously load, which will be increase more than 1.0 MPa near the fault of Damxung M6.3 earthquake in 2008, but the northern end of F2-1 is under Coulomb stress unloading, and the $\triangle C F S$ can reach -1.0 MPa. F2-2 will be under stress unloading as a whole (the $\triangle C F S$ can reach -1.0 MPa), and only the northeast end of F2-2 will be under stress loading (the $\triangle C F S$ can reach $0.1 \mathrm{MPa}$ ). The north and south of F2-3 will be under stress unloading as a whole (the $\triangle C F S$ can reach $-0.1 \sim-1.0 \mathrm{MPa}$ ), and only the middle of F2-3 will be under stress loading (the $\triangle C F S$ can reach $0.1 \mathrm{MPa}$ ). The northwest of F3 will be under stress loading as a whole (the $\triangle C F S$ can reach $1.0 \mathrm{MPa}$ ), and the southeast of $\mathrm{F} 3$ will be under stress loading (the $\triangle C F S$ can reach $-1.0 \mathrm{MPa}$ ).

\section{Discussion}

Seismic activity characteristics and trends

Chen et al. (Chen et al., 2001) believed that there had been 5 seismically active periods and 4 seismically quiet periods in China continent since 1900 . The distribution of seismicity period was shown in Table 5 . The b-value in the seismically active period was obviously lower than the b-value in the quiet period of the earthquake. The fifth round of seismically active period in China continent from 1988 may not have ended.

According to the seismicity in the study area, the author preliminarily identified the seismicity active period and quiet period (interval period). The division result was similar to that of Chen et al.(Chen et al., 2001), and there was a short-term quiet period in the active period. The division of seismicity active period and quiet period in this paper may be able to reflect the characteristics of seismicity in this area.

From the perspective of seismicity, seismicity is mainly divided into active period and quiet period. Based on the statistical analysis of the duration, frequency and energy of the active period, the development trend of the seismic active period can be determined. The trend of seismicity can be predicted by analyzing the b value of active period and stationary period (Chen et al., 2001; Liu et al., 2015).

The a-value describes a measure of the overall seismicity of the earthquake, which represents the total number of earthquakes or the severity of the frequency of seismic activity in the area. The $b$ value reflects the regional crustal rupture strength and stress state. A low $b$ value can be used as an indicator of high effective shear stress to determine the strong earthquake danger zone. The value of $a$ in the study area is high ( $a=4.240)$, which indicates that the total number of earthquakes in the area is high or the frequency of seismic activity is high(Xie et al., 2019). The $b$ value is relatively low $(b=0.530)$, and it is currently at a relatively high level of stress accumulation. It is more likely that moderate and strong earthquakes will occur in the future(Xie et al., 2019). It can be seen from Figure 2 that the first active period is 1920-1960 AD, the second active period is $1970-2010$ AD, each active period is 40 years, and the interval period is 10 years. Starting from 2020, the study area may enter a new active period.

Analysis of seismogenic fault

Since 1411 AD, the results of Coulomb stress evolution over the B-SPNM had evolved over time (Figure 4). The three strong earthquakes (Bengco M7.7 earthquake in 1951, Gulu M7.4 earthquake in 1952, and Damxung M6.3 earthquake in 2008) in the fault zone occurred under Coulomb stress loading due to a series of prior strong earthquakes. There was a trigger between strong earthquakes on the fault zone, and the increase of Coulomb stress generated after a large earthquake was conducive to the occurrence of subsequent earthquakes.

Table 6 shows the value of the Coulomb stress change at two points on the F2-1 fault plane in the next 100 years, 100 years after the Damxung M6.3 earthquake in 2008, the Coulomb stress of the YarlungZangbo fault will unload gradually. The overall Coulomb stress of F2-1 is in the loading stage, and the central Coulomb stress loading is more than $1.0 \mathrm{MPa}$ at point2, therefore, earthquakes will occur in this segment. F2-2 is in the stage of

Page $4 / 15$ 
Coulomb stress unloading, and the possibility of future earthquake is small. F2-3 is in the stage of Coulomb stress unloading, and the possibility of large earthquake is relatively small. The Coulomb stress in the northwest section of F3 is in the loading stage, and the loading amount of Coulomb stress is more than 1.0 MPa, so strong earthquakes will occur in the future in this segment.

From table 6 , as also observed by King et al.(King et al., 1995), $\mu$ ' controls mainly the magnitude of $\Delta$ CFS, rather than the overall pattern of stress loading lobes and stress shadows. Based on the considerations above, we carried out all our calculations with a value of effective friction of 0.4 .

The characteristic two-point Coulomb change value is shown as an example

Seismic analysis on different time scales

The earthquake catalog in this study area was incomplete, which may had a certain impact on the analysis of seismic activity characteristics. In view of the incompleteness of the earthquake catalog, the evaluation of its earthquake disaster parameters can be carried out by Kijko method (Kijko and Sellevoll, 1992). This article introduces the calculation method of Kijko to analyze the seismic activity of the study area in order to obtain the judgment of the possibility of future earthquakes in the region. Figure 6 shows the possibility of earthquakes of different magnitudes under different probability of exceedance. Figure 7 shows the return years of earthquakes of different magnitudes. Figure 8 shows the magnitude of earthquakes under different exceedance probabilities

It can be seen from figure 6 to figure $8, w$ hen the probability of exceedance in 100 years is $10 \%$, an earthquake with magnitude less than 7.8 may occur. The return year of M8 earthquake is at least 700 years. The maximum magnitude of earthquake in this area shall not exceed 9 . The maximum magnitude of the earthquake will be M6.7 in the future 100 years.

\section{Conclusion}

Through the research and analysis of this paper, The following conclusions and understandings are drawn from the present study:

(1) The seismicity level of the study area is high, and it is currently at a relatively high level of stress accumulation. It is more likely that moderate and strong earthquakes will occur in the future. The interval period is 10 years. Starting from 2020, the study area may enter a new active period. The maximum magnitude of the earthquake will be M6.7 in the future 100 years.

(2) There was a trigger between strong earthquakes on the Bengco - southeastern piedmont of Nyainqentanglha mountain (B-SPNM) fault zone, and the increase of Coulomb stress generated after a large earthquake was conducive to the occurrence of subsequent earthquakes

(3) The Coulomb stress in the northwest section of F3 and the middle segment of F2-1 are in the loading stage, and the central Coulomb stress loading is more than $1.0 \mathrm{MPa}$, so strong earthquakes will occur in the future in this two segments.

\section{Declarations}

\section{Acknowledgments}

Figure 1 was plotted using the Generic Mapping Tools (GMT) open-source collection of computer software Tools. Professor By A. Kijko provided great help for Estimation of earthquake hazard parameters from incomplete data files.

Authors' contribution

All authors contributed equally in the preparation of this manuscript.

Declaration of conflicting interests

The authors declared no potential conflicts of interest with respect to the research, authorship, and/or publication of this article.

Funding

The research reported in this paper was partially supported by the Science for Earthquake Resilience (XH20041), the National Natural Science Foundation of China (No.51908517).

Data Availability Statement

All data, models, and code generated or used during the study appear in the submitted article.

1) all authors agree with the submission, 2) the work has notbeen published elsewhere, either completely, in part, or in another form, and 3) the manuscript has not been submitted

to another journal. 


\section{References}

Administration, E.D.P.C.o.C.E. (1995). Catalogue of historical earthquakes in China (23rdcentury BC-1911 ADQ (Beijing: Seismological Press).

Administration, E.D.P.C.o.C.E. (1999). Catalogue of Chinese earthquakes in modern times (1912 AD-1990 AD, Ms $\geq 4.7$ ) (Beijing: General Science Press of China).

CENC (2020). The catalogue of earthquakes of China Earthquake Network Center.

CGIAR-CSI (2020). SRTM Data.

Chen, X.Z., Lu, X.J., and Wand, H.M. (2001). B value of the seismically active and quiescent periods and research of seismicty tendency in China's continent.

Christensen, N.I., and Mooney, W.D. (1995). Seismic velocity structure and composition of the continental crust: A global view. Journal of Geophysical Research: Solid Earth 100, 9761-9788.

Gao, X., Duan, Z.Q., Wang, W.M., and Guo, Z. (2010). Rupture process of the Oct.6,2008 M_s6.6 Damxung earthquake,Tibet,China. Chinese Journal of Geophysics 53, 2083-2090.

Gomberg, J., and Felzer, K. (2008). A model of earthquake triggering probabilities and application to dynamic deformations constrained by ground motion observations. Journal of Geophysical Research: Solid Earth 113.

Gu, G.X. (1983). Catalogue of Chinese earthquakes (Beijing: Science Press).

Gutenberg, B., and Richter, C. (1956). Earthquake magnitude, intensity, energy, and acceleration (Second paper). Bulletin of the Seismological Society of America 46.

Haines, S.S., Klemperer, S.L., Brown, L., Jingru, G., Mechie, J., Meissner, R., Ross, A., and Wenjin, Z. (2003). INDEPTH III seismic data: From surface observations to deep crustal processes in Tibet. Tectonics 22.

Harris, R.A. (1998). Introduction to special section: Stress triggers, stress shadows, and implications. J Geophys Res 103, $347-424$.

Jiao, Q.S., Zhang, J.F., and Jiang, W.L. (2015). Geomorphic features and remote sensing research of fault activity along the southeastern piedmont faults of Nyenchen Tonglha Mountains. Seismology and geology 37, 613-626.

Kijko, B.A., and Sellevoll, M.A. (1992). Estimation of earthquake hazard parameters from incomplete data files. Part II. Incorporation of magnitude heterogeneity. Bulletin of the Ssmological Society of America 82, 120-134.

King, G.C.P., Stein, R.S., and Lin, J. (1995). Static stress changes and the triggering of earthquakes: G. C. P. King, R. S. Stein \& Jian Lin, Bulletin Seismological Society of America, 84(3), 1994, pp 935-953. International Journal of Rock Mechanics and Mining Sciences \& Geomechanics Abstracts 32, A50-A51.

Liu, F., Yuan, D., Wang, A., and Pang, W. (2015). Comparative analysis on stress triggering of double earthquakes sequence and seismicity in southwest part of Yunnan Province. Earthquake Research in China.

Peng, X.L., and Wang, D.Y. (2013). Tectonic characteristics and activity analysis of the Yarlung Zangbojiang fault zone. Jounal of Yangtze University(Nat Sci Edit) 10, 41-44.

Qiao, X.J., You, X.Z., Yang, S.M., Wang, Q., and Du, R.L. (2009). Study on Dislocation Inversion of Ms6.6 Damxung Earthquake as constrained by InSAR Measurement. Journal of Geodesy and Geodynamics 29, 1-7.

Shan, B., Feng, Y., Liu, C., Xie, Z., and Xiong, X. (2020). Stress triggering among faults rupturing during one earthquake: a case study of the 2016 Mw7.8 Kaikōura Earthquake, New Zealand. Science Bulletin 65, 89-91.

Shi, Y.L., and Cao, J.L. (2008). Effective viscosity of China continental lithosphere. Earth Science Frontiers 15, 0-0.

Stein, R. (2003). Earthquake Conversations. Scientific American 288, 72-79.

Stein, R.S. (1999). The role of stress transfer in earthquake occurrence. Nature 402, 605-609.

Stein, R.S., King, G.C.P., and Lin, J. (1992). Change in Failure Stress on the Southern San Andreas Fault System Caused by the 1992 Magnitude $=7.4$ Landers Earthquake. Science 258, 1328-1332.

USGS (2020). Earthquakes. 
Verdecchia, A., and Carena, S. (2015). One hundred and fifty years of Coulomb stress history along the California-Nevada border, USA. Tectonics 34, 213-231.

Wang, C.Y., Lou, H., Lv, Z.Y., Wu, J.P., Chang, L.J., Dai, S.G., You, H.C., Tang, F.T., Zhu, L., and Silver, P. (2008). S-wave crustal and upper mantle's velocity structure in the eastern Tibetan Plateau--Deep environment of lower crustal flow. Science China Earth Sciences 38, $263-274$.

Wang, R., Lorenzo-Martín, F., and Roth, F. (2006). PSGRN/PSCMP-a new code for calculating co- and post-seismic deformation, geoid and gravity changes based on the viscoelastic-gravitational dislocation theory. Computers \& Geosciences 32, 527-541.

Wu, Z.M., Cao, Z.Q., Shen-tu, B.M., and Deng, Q.D. (1992). Active Faults in the Central TIbet (Beijing: Seismological Press).

Xie, Z.J., Lv, Y.J., Fang, Y., and Zhang, Y.L. (2019). Research on the seismic activity of the Beijing-Tianjin-Hebei region. Progress in Geophysics 34, 961968.

Yang, G., Wu, J., Hu, Q., and Cai, Y. (2019). Effects of static stress triggering of the strongest earthquakes along the Bengco-southeastern Piedmont of Nyainqentanglha mountain fault zone, Tibet. Journal of Seismology 23, 943-950.

Yin, F.L., Han, L.B., Jiang, C.S., and Shi, Y.L. (2018). Interaction between the 2017 M6.9 Mainling earthquake and the 1950 M8.6 Zayu earthquake and their impacts on surrounding major active faults. Chinese Journal of Geophysics 61, 3185-3197.

Zhao, W., Mechie, J., Brown, L.D., Guo, J., Haines, S., Hearn, T., Klemperer, S.L., Ma, Y.S., Meissner, R., Nelson, K.D., et al. (2001). Crustal structure of central Tibet as derived from project INDEPTH wide-angle seismic data. Geophysical Journal International 145, $486-498$.

\section{Tables}

Table 1 A cumulative annual mean incidence of earthquake in different time period of Central Tibet

\begin{tabular}{|c|c|c|c|c|c|c|c|c|c|c|c|c|c|c|}
\hline \multirow[t]{2}{*}{ Time } & & \multicolumn{13}{|l|}{ M } \\
\hline & & 2.0 & 2.5 & 3.0 & 3.5 & 4.0 & 4.5 & 5.0 & 5.5 & 6.0 & 6.5 & 7.0 & 7.5 & 8.0 \\
\hline \multirow{2}{*}{$\begin{array}{l}1400- \\
2019\end{array}$} & $\mathrm{~N}$ & - & - & - & - & - & - & 71 & 45 & 19 & 10 & 3 & 3 & 1 \\
\hline & V & - & - & - & - & - & - & 0.1147 & 0.0727 & 0.0307 & 0.0161 & 0.0048 & 0.0048 & 0.0016 \\
\hline \multirow{2}{*}{$\begin{array}{l}1900- \\
2019\end{array}$} & $\mathrm{~N}$ & - & - & - & - & - & - & 69 & 43 & 18 & 9 & 2 & 2 & 0 \\
\hline & V & - & - & - & - & - & - & 0.5798 & 0.3613 & 0.1513 & 0.0756 & 0.0168 & 0.0168 & 0 \\
\hline \multirow{2}{*}{$\begin{array}{l}1950- \\
2019\end{array}$} & $\mathrm{~N}$ & - & - & - & - & 105 & 78 & 56 & 33 & 12 & 7 & 2 & 2 & 0 \\
\hline & V & - & - & - & - & 1.5217 & 1.1304 & 0.8116 & 0.4783 & 0.1739 & 0.1014 & 0.0290 & 0.0290 & 0 \\
\hline \multirow{2}{*}{$\begin{array}{l}1970- \\
2019\end{array}$} & $N$ & 1514 & 895 & 473 & 168 & 80 & 53 & 36 & 21 & 7 & 4 & 0 & 0 & 0 \\
\hline & V & 30.8980 & 18.2653 & 9.6531 & 3.4286 & 1.6327 & 1.0816 & 0.7347 & 0.4286 & 0.1429 & 0.0816 & 0 & 0 & 0 \\
\hline
\end{tabular}

Table 2 Parameters of the multilayer crustal mode

\begin{tabular}{|llllll|}
\hline No. & $\begin{array}{l}\text { Depth range } \\
(\mathrm{km})\end{array}$ & $\begin{array}{l}\text { P wave speed } \\
\left(\mathrm{km} \cdot \mathrm{s}^{-1}\right)\end{array}$ & $\begin{array}{l}\text { S wave speed } \\
\left(\mathrm{km} \cdot \mathrm{s}^{-1}\right)\end{array}$ & $\begin{array}{l}\text { Density } \\
\left(\mathrm{kg} \cdot \mathrm{m}^{-3}\right)\end{array}$ & $\begin{array}{l}\text { Viscosity coefficient } \\
(\mathrm{Pa} \cdot \mathrm{s})\end{array}$ \\
\hline 1 & $0-4$ & 5.00 & 2.89 & 2570 & $\infty$ \\
\hline 2 & $4-20$ & 6.00 & 3.47 & 2713 & $\infty$ \\
\hline 3 & $20-35$ & 6.25 & 3.61 & 2800 & $\infty$ \\
\hline 4 & $35-45$ & 6.50 & 3.76 & 2925 & $\infty$ \\
\hline
\end{tabular}

Table 3 Parameters of seismic dislocation model 


\begin{tabular}{|llllllllll|}
\hline NO. & Date & Long/Lat $\left(^{\circ}\right)$ & $M$ & Location & Strike/Dip/Rake $\left(^{\circ}\right)$ & Length $(\mathrm{km})$ & Width(km) & Left-lateral(m) & Dip slip $(\mathrm{m})$ \\
\hline 1 & Sep 28, 1411 & $90.5 / 30.1$ & 8.0 & Damxung & $45 / 58 /-42$ & 108 & 35 & 2.60 \\
\hline 2 & Nov 18, 1951 & $91.4 / 31.1$ & 7.7 & Bengco & $303 / 78 /-165$ & 81 & 28 & -1.93 \\
\hline 3 & Aug 17, 1952 & $91.601 / 30.648$ & 7.4 & Gulu & $13 / 67 /-142$ & 57.7 & 23 & -1.35 & 0.52 \\
\hline 4 & Oct 6, 2008 & $90.350 / 29.807$ & 6.3 & Damxung & $183.3 / 29.5 /-115$ & 12 & 11 & -0.55 \\
\hline
\end{tabular}

Table 4 Parameters of surrounding faults

\begin{tabular}{|lllll|}
\hline Fault & $\left.\operatorname{Strike}^{\circ}\right)$ & $\operatorname{Dip}\left({ }^{\circ}\right)$ & $\operatorname{Rake}\left({ }^{\circ}\right)$ & Length $(\mathrm{km})$ \\
\hline F1 & 107 & 68 & 90 & 290 \\
\hline F2-1 & 8 & 80 & -90 & 116 \\
\hline F2-2 & 45 & 58 & -42 & 135 \\
\hline F2-3 & 13 & 67 & -142 & 58 \\
\hline F3 & 303 & 78 & -165 & 106 \\
\hline
\end{tabular}

F1 from(Peng and Wang, 2013) , F2-1, F2-2, F2-3 and F3 from(Wu et al., 1992; Yang et al., 2019)

Table 5 Division of active and quiet periods in Chinese continent

\begin{tabular}{|llllllllll|}
\hline Period & First cycle & \multicolumn{2}{l}{ Second cycle } & & Third cycle & & Fourth cycle & & Fifth cycle \\
\cline { 2 - 9 } & active & quiet & active & quiet & active & quiet & active & quiet & active \\
Year & $1900 \sim 1912$ & $1912 \sim 1920$ & $1920 \sim 1938$ & $1938 \sim 1946$ & $1946 \sim 1957$ & $1957 \sim 1966$ & $1966 \sim 1976$ & $1976 \sim 1987$ & $1988 \sim$ \\
\hline
\end{tabular}

Table 6 Coulomb stress change value (KPa) on the F2-1 fault plane in the next 100 years

\begin{tabular}{|llllll|}
\hline Position & Year & \multicolumn{5}{c|}{ Different viscosity value } \\
\cline { 2 - 6 } & & 0.2 & 0.4 & 0.6 & 0.8 \\
\hline Point $\left(90.26^{\circ} \mathrm{E} / 29.20^{\circ} \mathrm{N}\right)$ & 2033 & 5.2 & 8.7 & 12.4 & 16.1 \\
\cline { 2 - 7 } & 2058 & 5.4 & 9.1 & 12.9 & 16.7 \\
\cline { 2 - 7 } & 2083 & 6.3 & 9.5 & 13.6 & 17.6 \\
\hline Point2 $\left(90.28^{\circ} \mathrm{E} / 29.84^{\circ} \mathrm{N}\right)$ & 2108 & 6.8 & 10.5 & 14.6 & 18.8 \\
& 2033 & 1163.4 & 1618.6 & 2076.1 & 2533.6 \\
\cline { 2 - 7 } & 2058 & 1169.2 & 1630.4 & 2092.3 & 2554.9 \\
\hline 2083 & 1174.3 & 1640.2 & 2106.3 & 2572.7 \\
\hline & 2108 & 1179.1 & 1648.7 & 2117.9 & 2587.6 \\
\hline
\end{tabular}

\section{Figures}




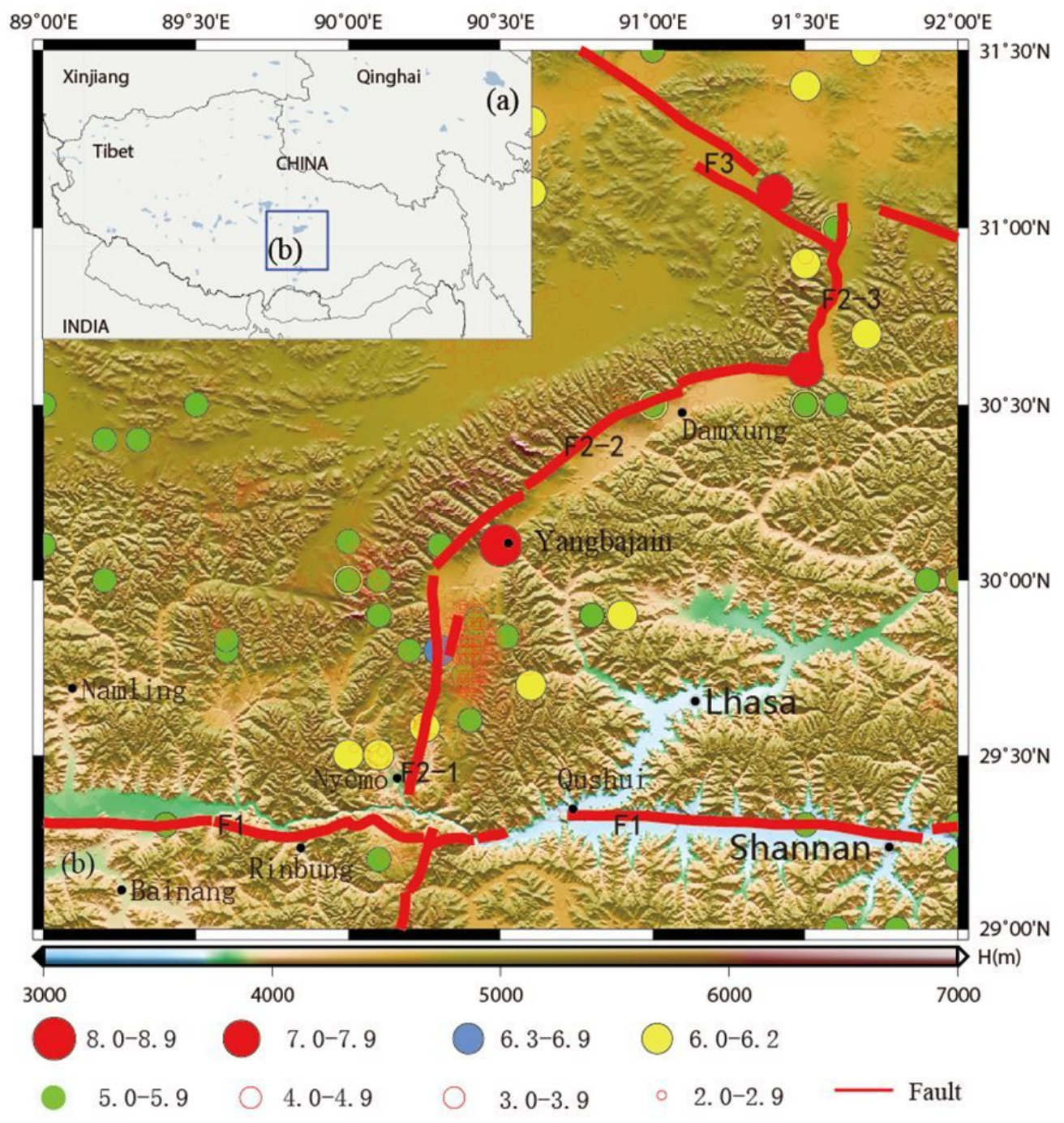

\section{Figure 1}

Seismotectonic map of the central Tibet. F1 is the YarlungZangbo fault, F2 is the SPFNM (F2-1 Nimu segment, F2-2 Damxung-Yangbajain segment, F23 Gulu segment), F3 is the Bengco fault. DEM data from(CGIAR-CSI, 2020). 

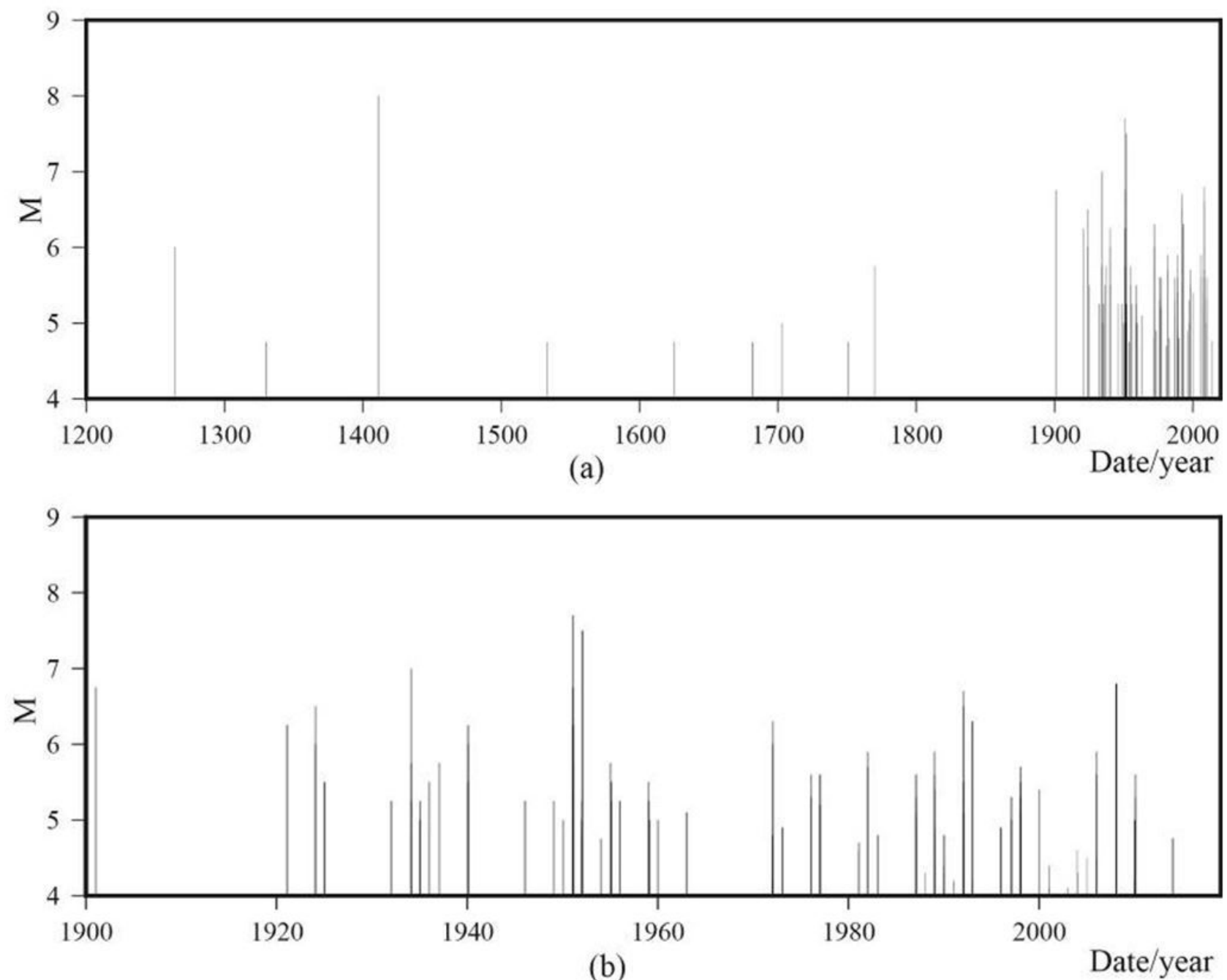

Figure 2

(a) M-T maps of the study area since 1200; (b) M-T maps of the study area since 1900 


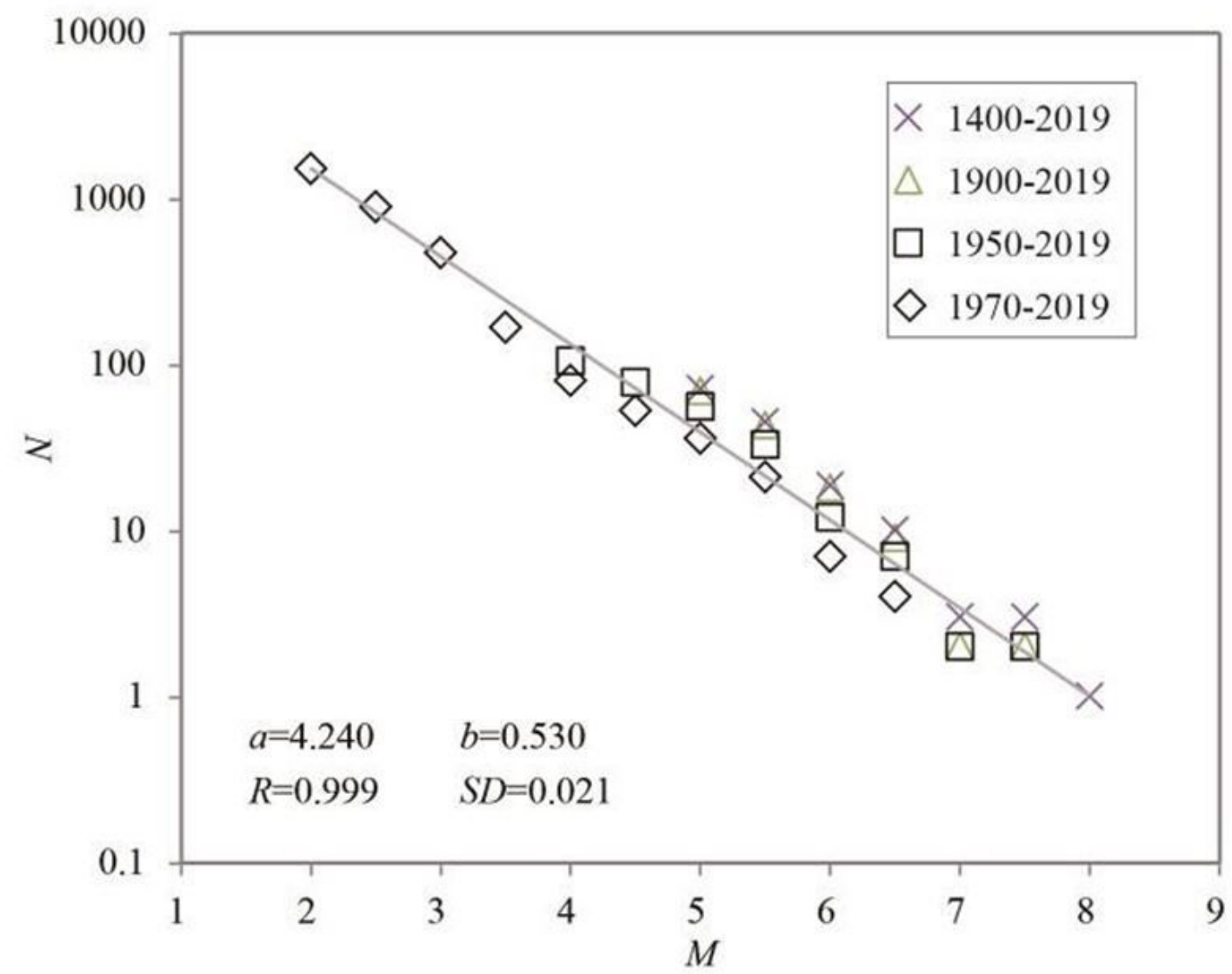

Figure 3

Magnitude-frequency relationship of Central Tibet
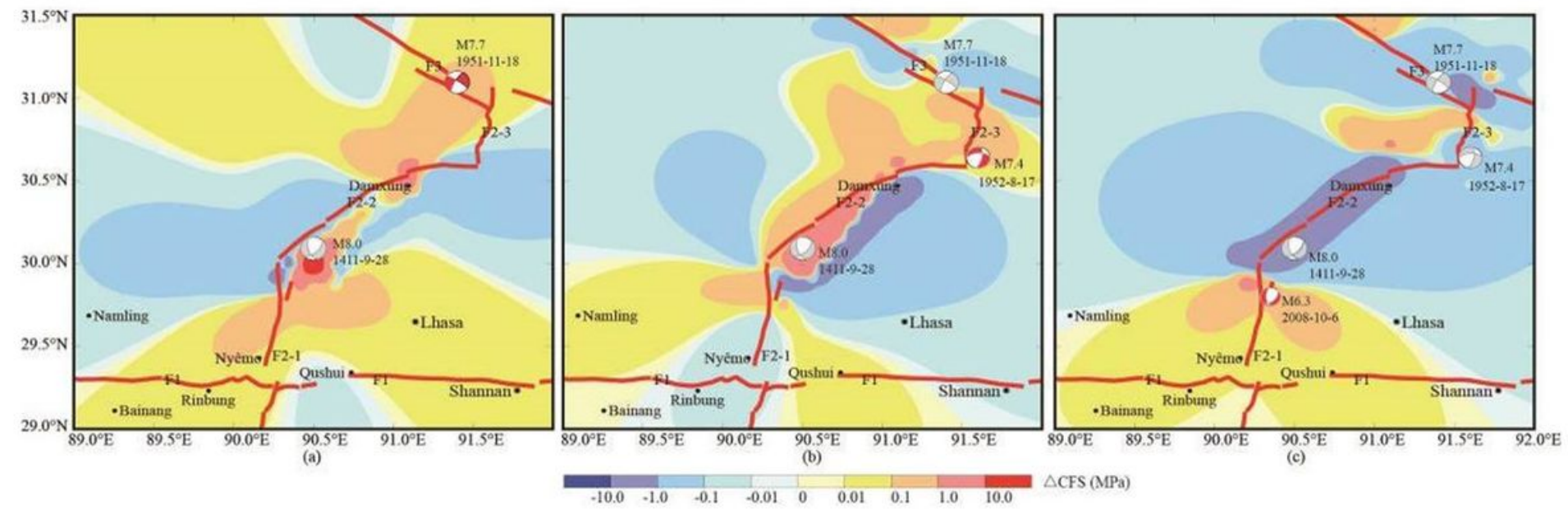

Figure 4

Coulomb failure stress changes caused by the post-seismic dislocations on the fault zone 


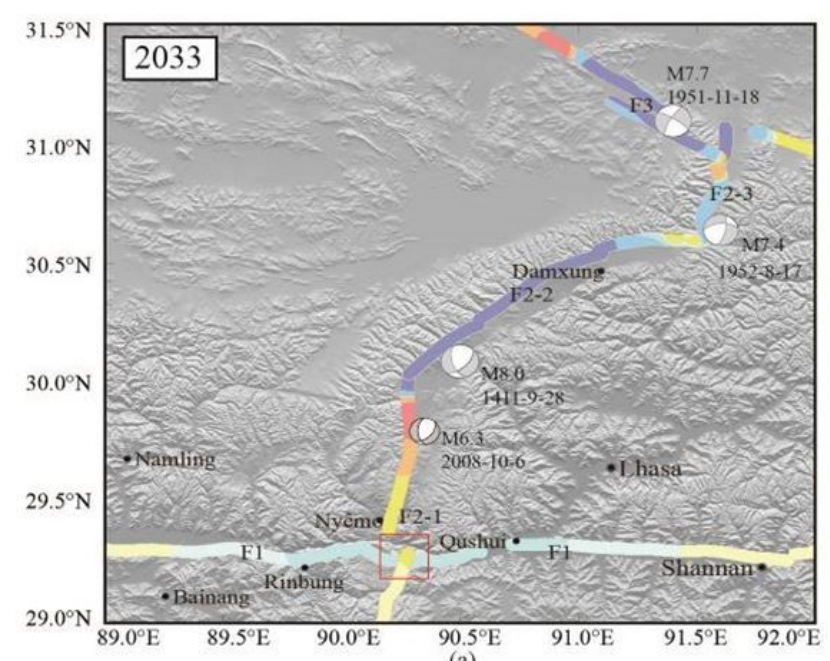

(a)

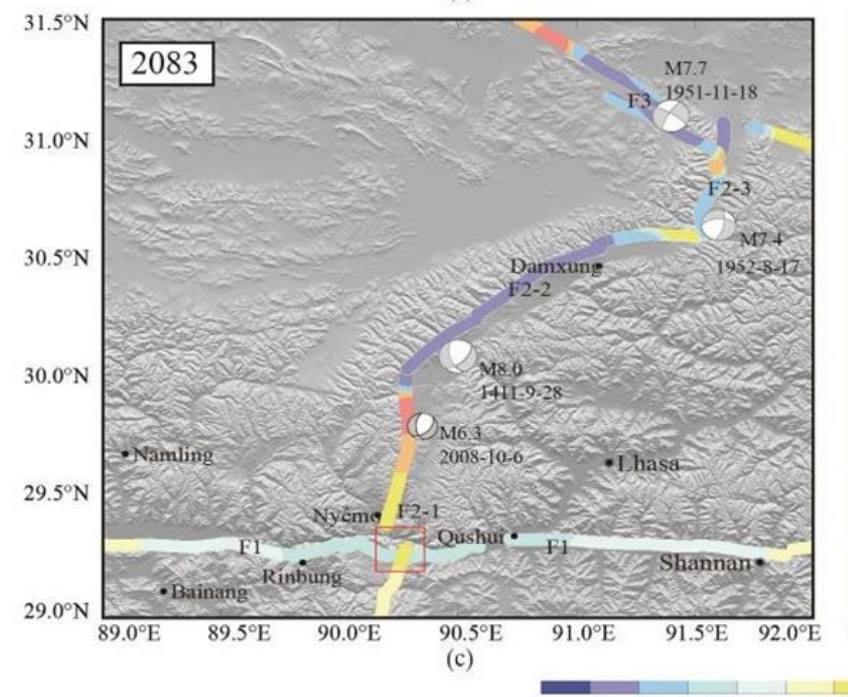

$\begin{array}{ccccccccc}-10.0 & -1.0 & -0.1 & -0.01 & 0 & 0.01 & 0.1 & 1.0 & 10.0\end{array}$

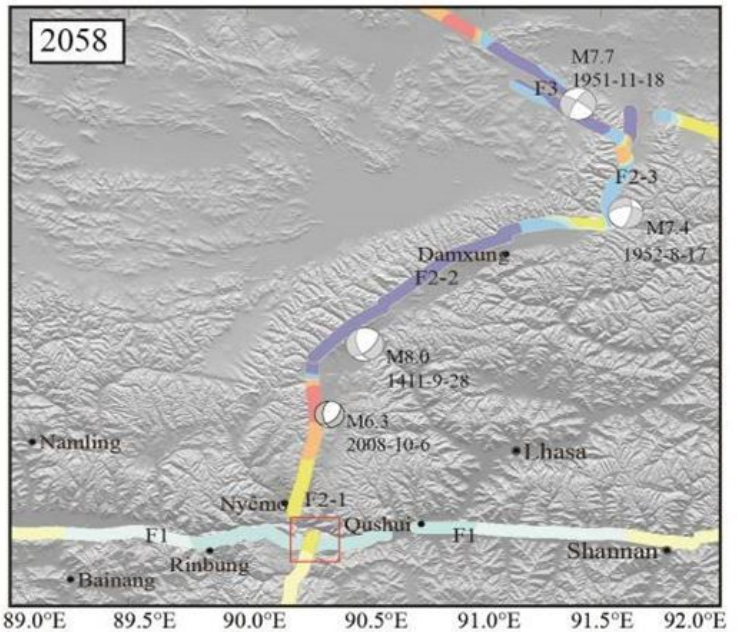

(b)

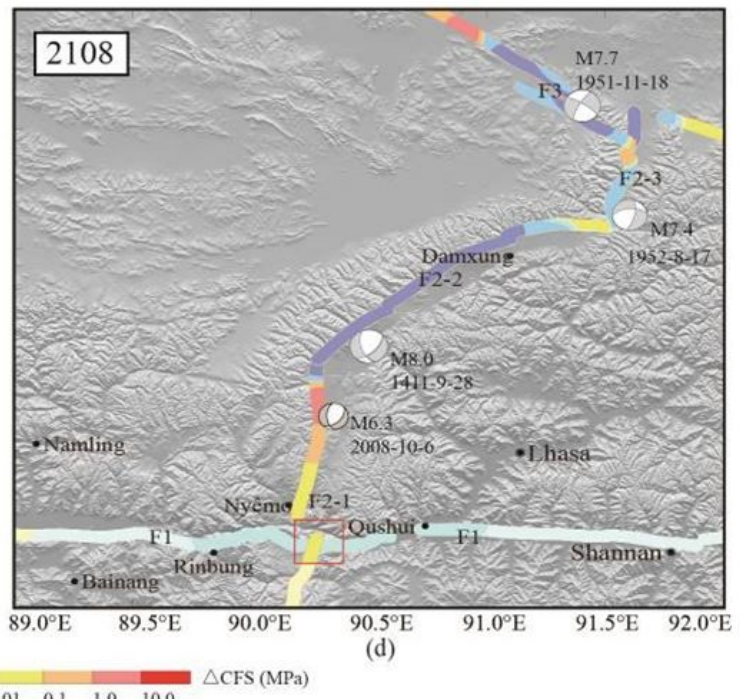

\section{Figure 5}

The time-dependent CFS evolution on the active faults caused by 4 strong earthquakes 


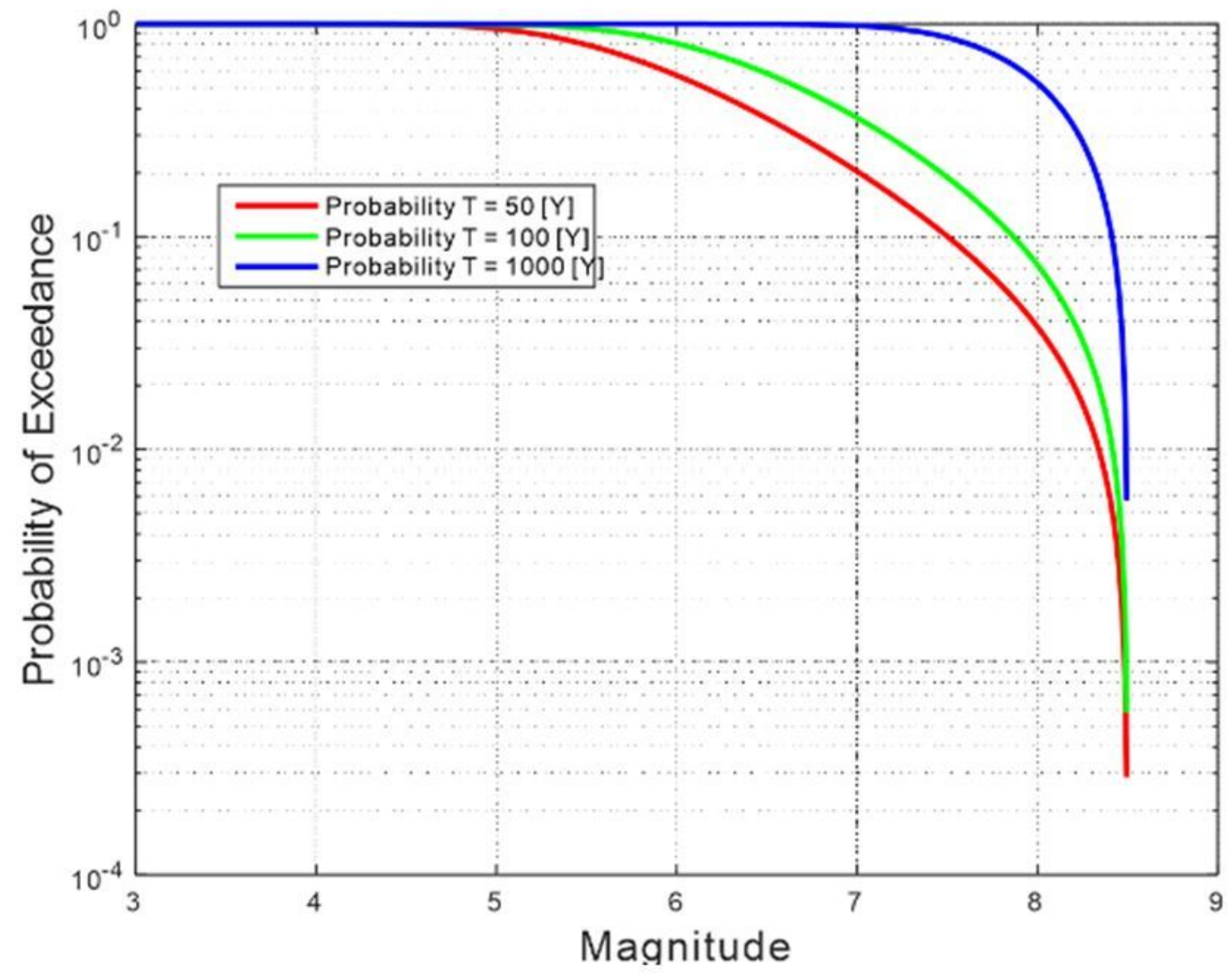

Figure 6

The map of different probability of exceedance-Magnitude 


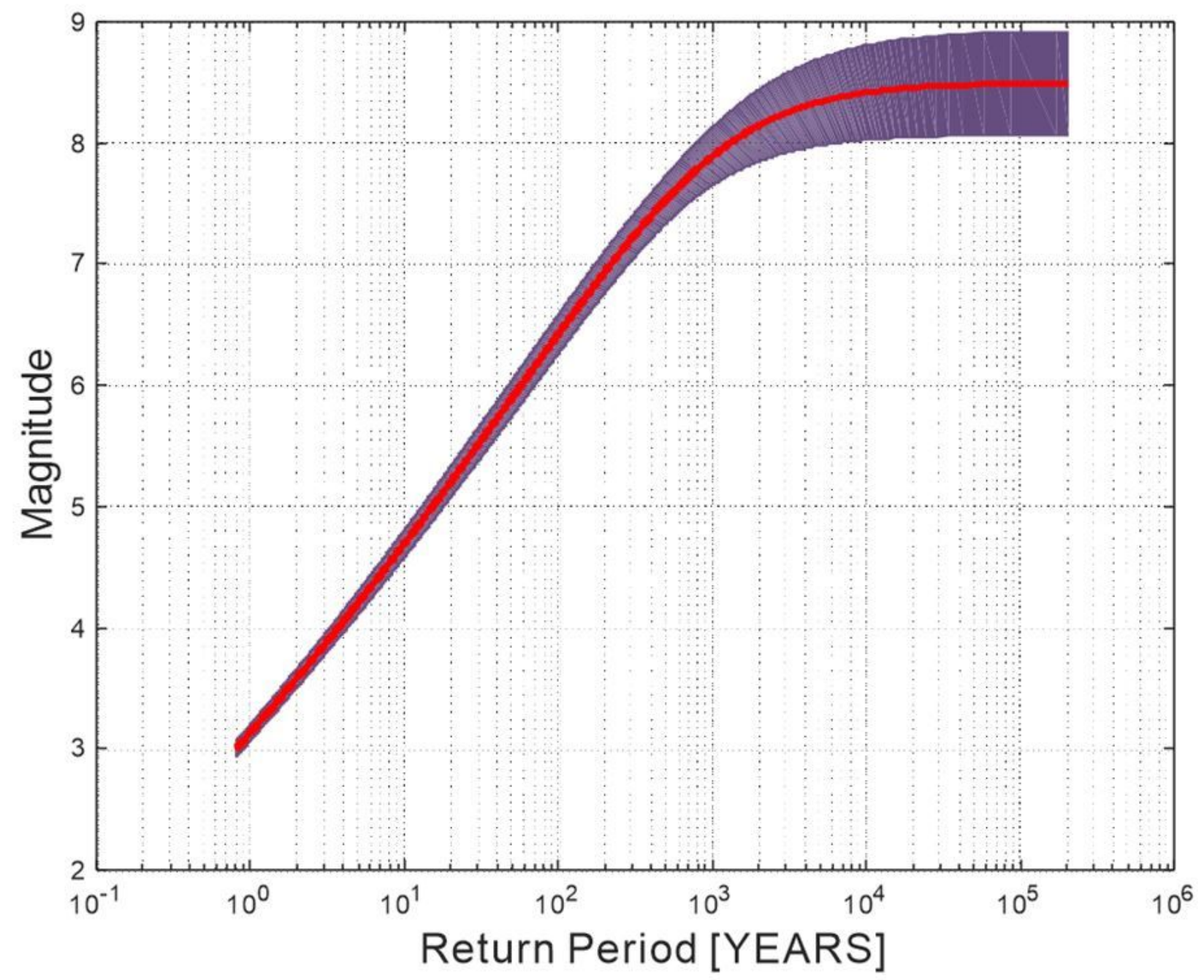

Figure 7

The map Magnitude - Return Period 


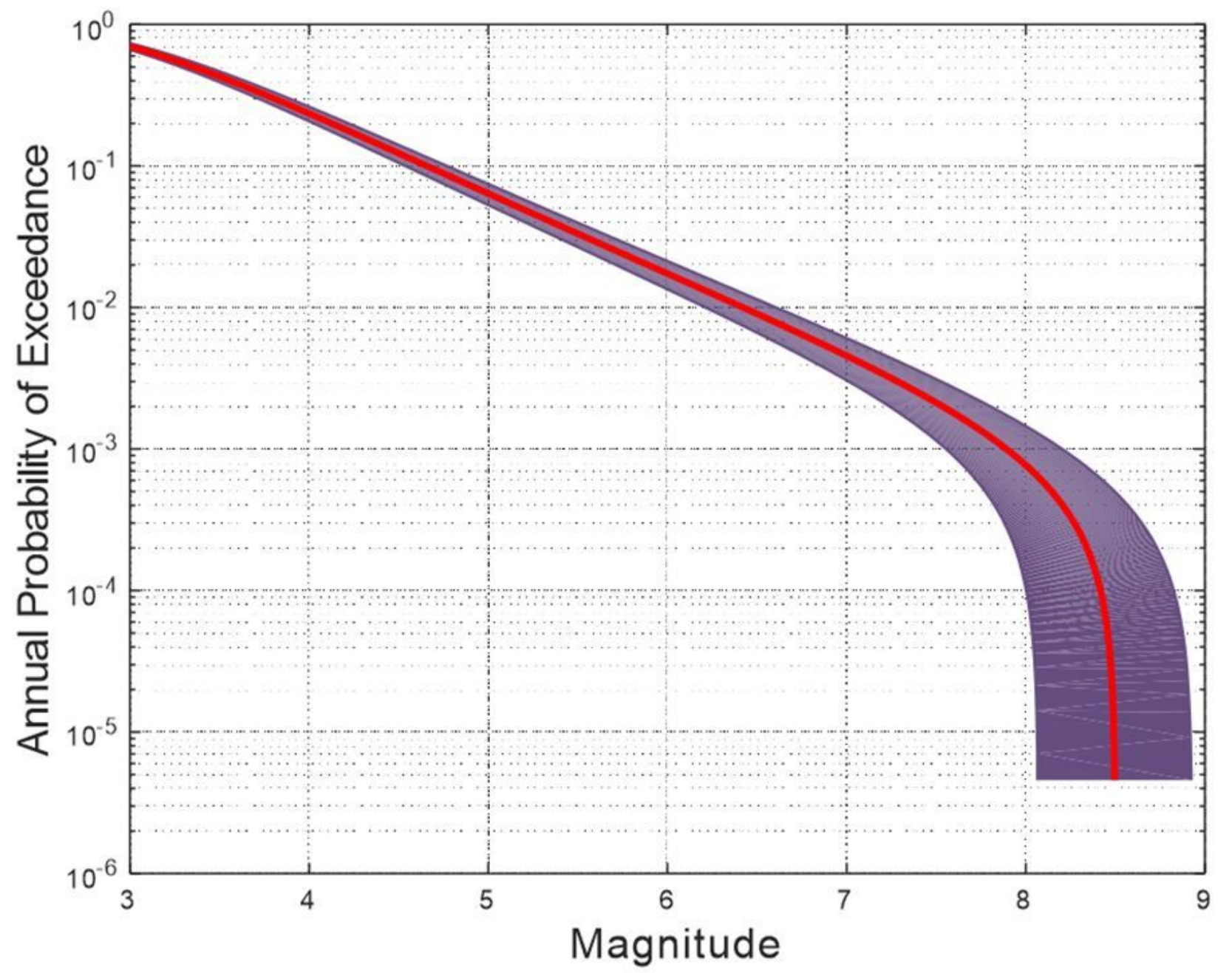

Figure 8

The map Annual Probability of Exceedance - Magnitude 